\title{
MBBR efficiency improvement by varying the carrier element fraction
}

\author{
Parul Saler* and Harshavardhan Patil** \\ $*$ Research guide $* *$ Research student
}

Department of Environmental Engineering, KIT's college of Engineering (autonomous), Kolhapur, Maharashtra, India

\begin{abstract}
Moving-Bed Bioreactors (MBBRs) are commonly used for treatment of combined effluent treatment (domestic and industrial effluent combination). While MBBRs usually give significant reduction in pollutants, the carrier element fraction also plays an important role. If the carrier element concentration becomes too high, the micro-organisms get detached from the surface and get removed out of the system. This lowers the pollutant removal efficiency. Also, if the carrier element concentration is too high, more aeration is required to keep them in suspended form and increases operation cost of the plant. Hence, optimization of carrier element concentration is crucial for efficient effluent treatment. The main objective of this study was to understand correlation of carrier element fraction to the COD and phosphate removal. Based on the results obtained for the effluent selected for study, $60 \%$ carrier element fraction was found to be optimum in reduction of COD \& phosphate.
\end{abstract}

Keywords: Moving bed bioreactors, biological treatment, COD removal, Phosphate removal

1. Introduction:

\subsection{Biological treatment}

Biological treatment is used in effluent treatment to breakdown organic wastes using microorganisms using normal cellular processes. Microorganisms oxidize the particulate \& dissolved organic matter containing carbon to a product that is simple in nature $\&$ some excess biomass.

Chemical reaction:

$\mathrm{V}_{1}($ organic material $)+\mathrm{V}_{2} \mathrm{O}_{2}+\mathrm{V}_{3} \mathrm{NH}_{3}+\mathrm{V}_{4} \mathrm{PO}_{43-} \rightarrow \mathrm{V}_{5}($ new cells $)+\mathrm{V}_{6} \mathrm{CO}_{2}+\mathrm{V}_{7} \mathrm{H}_{2} \mathrm{O}$

Oxygen, ammonia and phosphate are utilized by microorganisms to convert organic matter into $\mathrm{CO}_{2}$ \& water. New cells indicate biomass generated because of organic matter oxidation. (Metcalf \&Eddy, 2003)

The biodegradability of effluent depends on the BOD: COD ratio.

easily biodegradable $(>0.5)$

average biodegradable $(0.4-0.5)$

slowly biodegradable $(0.2-0.4)$

not biodegradable $(<0.2)$ 


\section{Moving Bed Biofilm Reactor (MBBR):}

This process was established in Norway University of Science and Technology cooperation with Norwegian company Kaldnes Miljóteknologi (now AnoxKaldnes AS) during the late 1980 and early 1990. Ødegaard, et al., (2007). They concluded that the MBBR represented a different spectrum in advanced wastewater treatment. MBBR were operated similarly to the activated sludge process with the addition of freely moving carrier media.

Moving-Bed Bioreactors (MBBRs) utilize attached growth media as a substrate for the development of treatment biofilms. This media is spread in aerated treatment reactors ensuring optimum level of oxygen and substrate transfer to the biomass. MBBR reactors are used for both aerobic and anoxic processes. For MBBR process, higher surface area ensures more space of growth of microbial film and denser layer resulting in high efficiency of pollutant removal. However, if the carrier element concentration becomes too high, the micro-organisms get detached from the surface and get removed out of the system. This lowers the pollutant removal efficiency. Also, if the carrier element concentration is too high, more aeration is required to keep them in suspended form and increases operation cost of the plant. Hence, optimization of carrier element concentration is crucial for efficient effluent treatment.

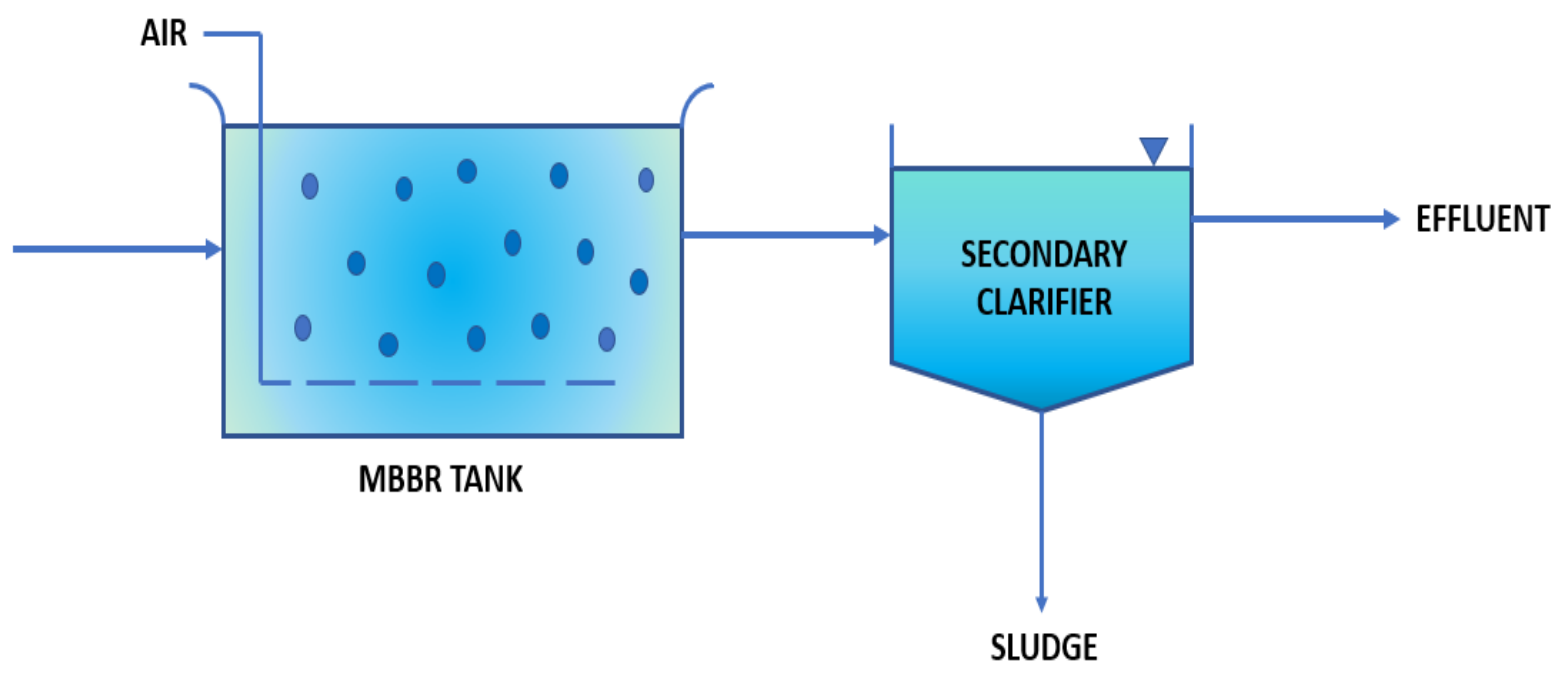

Fig 1: Schematic Diagram of MBBR

The main objective of this study is to study effect of various carrier element concentrations and its subsequent effect on removal of COD, BOD, TSS, TDS and TP.

\subsection{Experimental set-up:}

The study was conducted on an experimental model:

Volume $($ lit $)=20$ liters 
Water volume $=10$ liters

Media volume $=$ varied from 7 liters to 4 liters

Filling ratio with carriers $\%=$ varied from $70 \%$ to $40 \%$

Model type $=$ Fill and draw

Material= acrylic with metal taps

Aerators $=2$

Capacity of aerators $=0.3 \mathrm{lit} / \mathrm{min}$

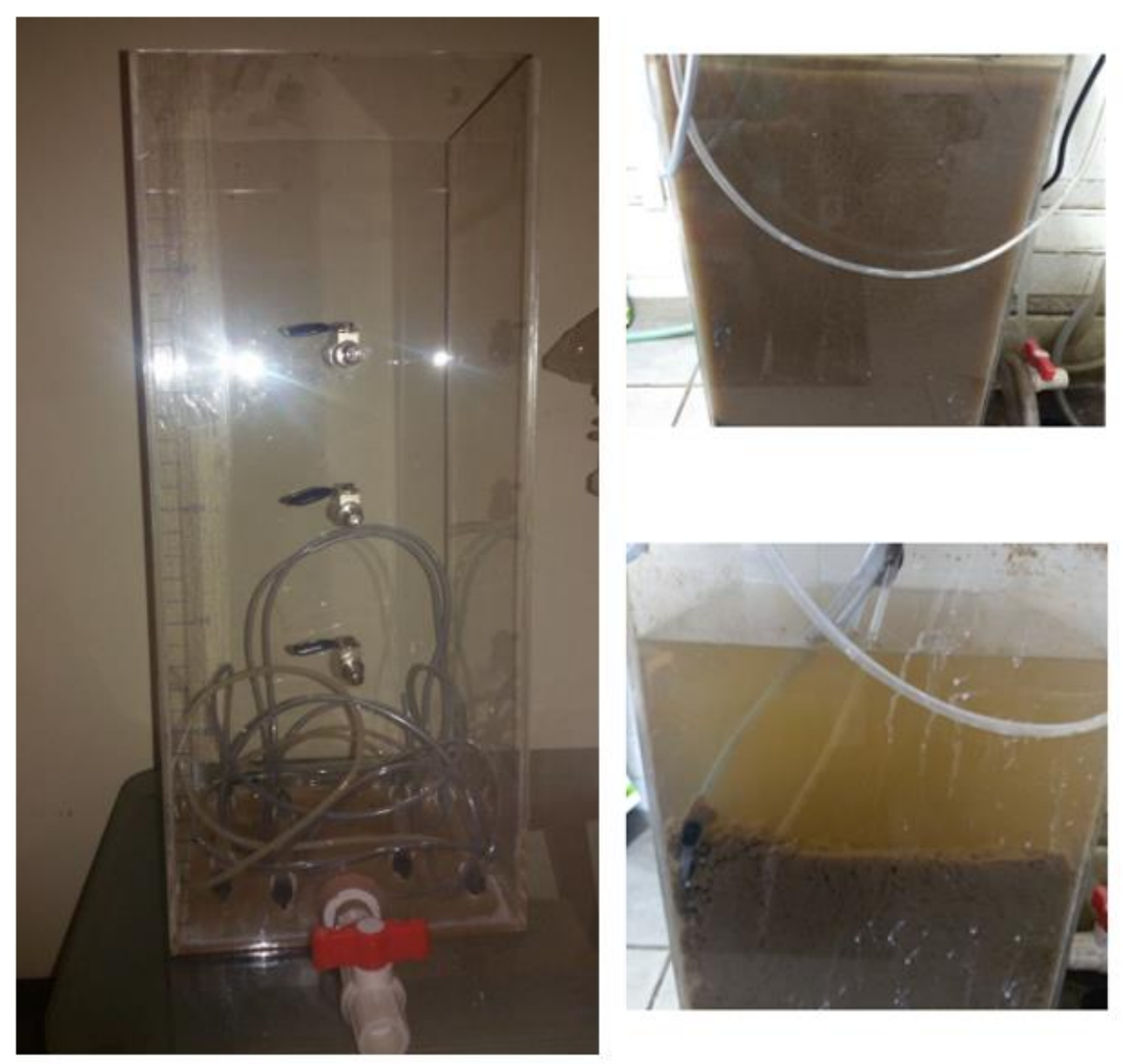

Figure 2: MBBR experimental set-up

\section{$\underline{\text { Carrier element details }}$}

Material= Poly ethylene

Shape $=$ Porous rod shaped

Density $=0.96-0.98 \mathrm{~g} / \mathrm{cm}^{2}$ 


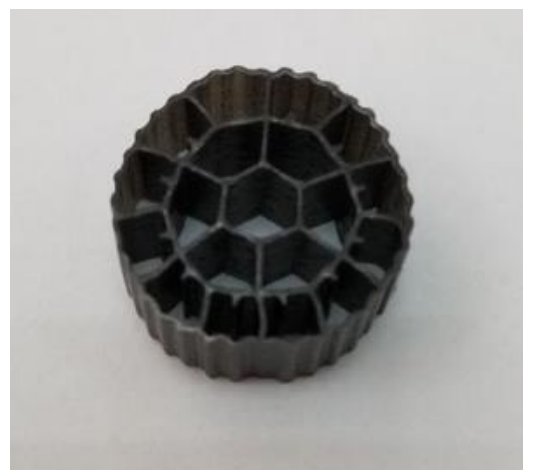

Figure 3: MBBR carrier element

\section{Micro-organisms:}

Active MLSS for the industry's CETP treatment plant was used. The carrier elements were submerged in a mixture of bio culture and cow dung for 15 days in order to develop biofilm on the surface of the carrier.

\subsection{Process:}

- Parameter analysis for inlet effluent was conducted for each batch

- 10 liters sample from the equalization tank of the existing treatment plant was subjected to biodegradation in the MBBR model

- MBBR carrier element were varied from $70 \%$ to $40 \%$

- Each carrier element concentration selected was maintained for one week (6 cycles)

- After treatment parameter analysis was conducted for each cycle

- Effect of carrier element concentration was analyzed based on removal efficiency of COD

\subsection{Analysis:}

All parameter analysis was conducted as per standard methods (American public health association (APHA), 1998 at the in-house lab of the industry.

2. Result of MBBR carrier element concentration variation

2.1 Morphology of biofilm:

The morphology of the biofilm varied based on the carrier element concentration. When the carrier element fraction concentration is low the biofilm was fluffy and not very firm, and it covers all the carrier element surface. But when the concentration is increased, the biofilm becomes dense, firm and thin.

Also, higher concentration leads to more abrasion amongst the carrier elements leading to filamentous bacteria being scuffed off.

2.2 Biomass: 
Development of biomass is a constant process where attached bacteria get detached from the surface while the bacteria in suspended position get attached to the surface. Along with this, the process of multiplication of bacteria goes on as well. Steady state biofilm is developed during equilibrium state. Variation of biomass concentration can be seen in graph no..... Based on suspended microbial concentration (MLSS) and sludge volume index. When the carrier element concentration was lower, the biomass was mostly in suspended state. When the carrier element concentration started increasing, the room for suspended biomass started reducing resulting in suspended biomass occupying an extremely low area at ...\%

Table 1: SV30 for varying carrier element concentrations

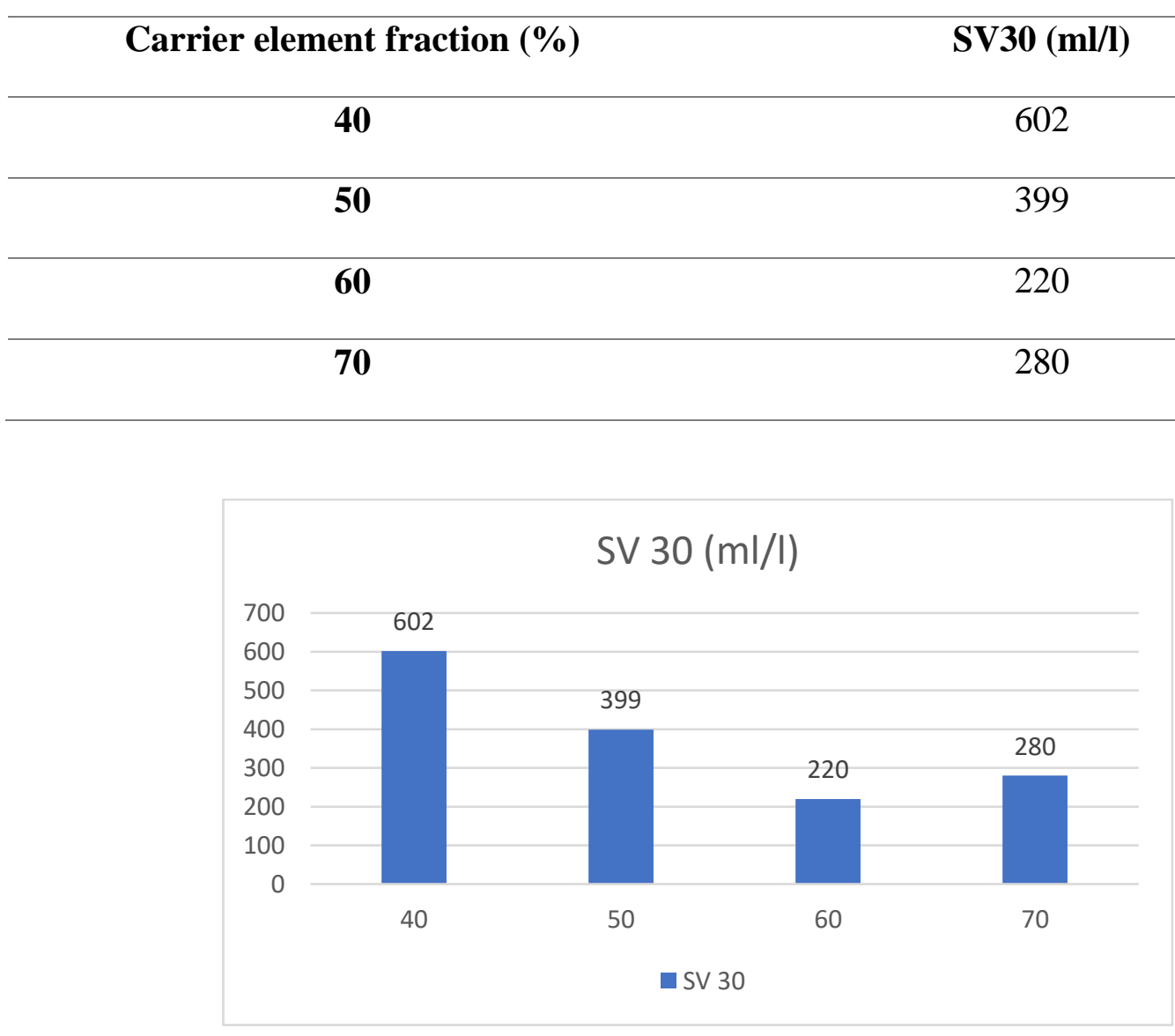

Fig 4: Graph of SV30 for varying carrier element concentrations

Table 2: MLSS concentration for varying carrier element concentrations

\begin{tabular}{cc}
\hline Carrier element concentration (\%) & MLSS (mg/l) \\
\hline $\mathbf{4 0}$ & 4585 \\
\hline $\mathbf{5 0}$ & 3702 \\
\hline $\mathbf{6 0}$ & 2856 \\
\hline $\mathbf{7 0}$ & 3079 \\
\hline
\end{tabular}




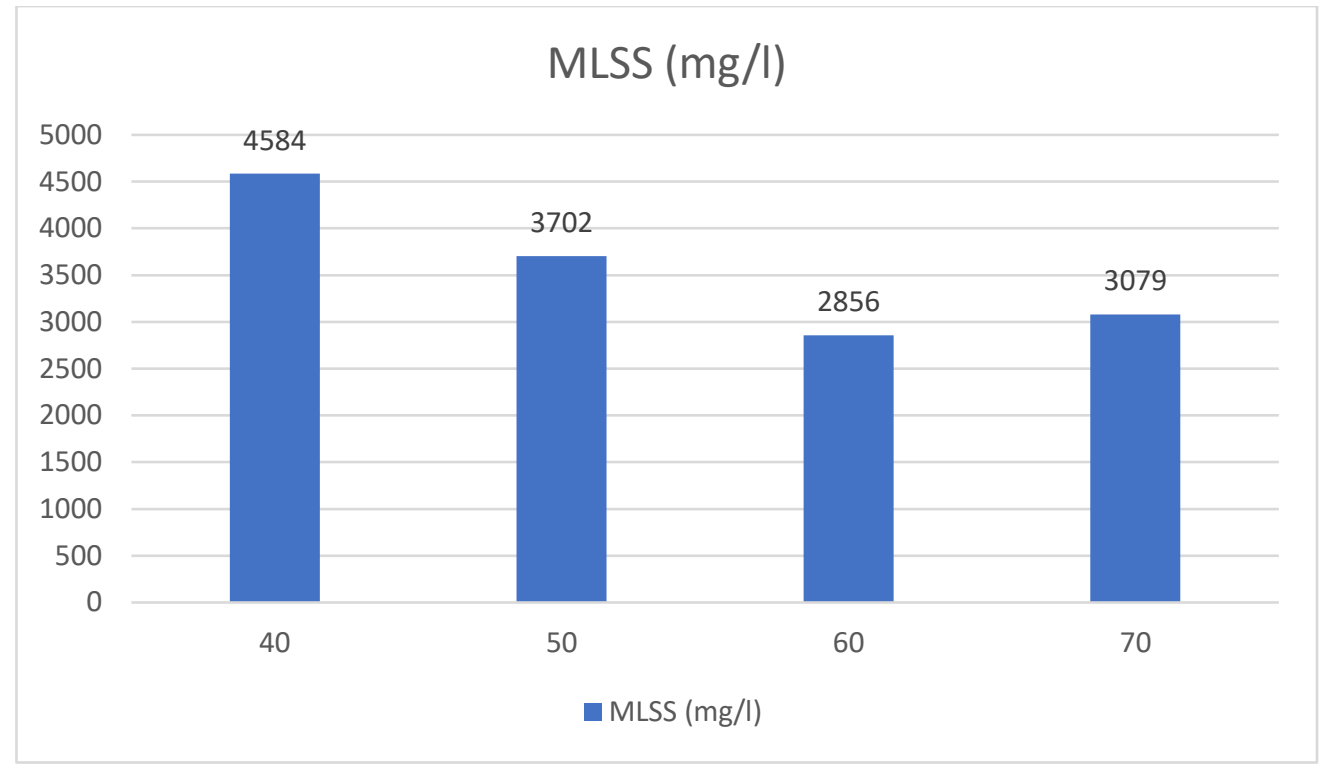

Fig 5: Graph of MLSS concentration for varying carrier element concentrations

Table 3: SVI for varying carrier element concentrations

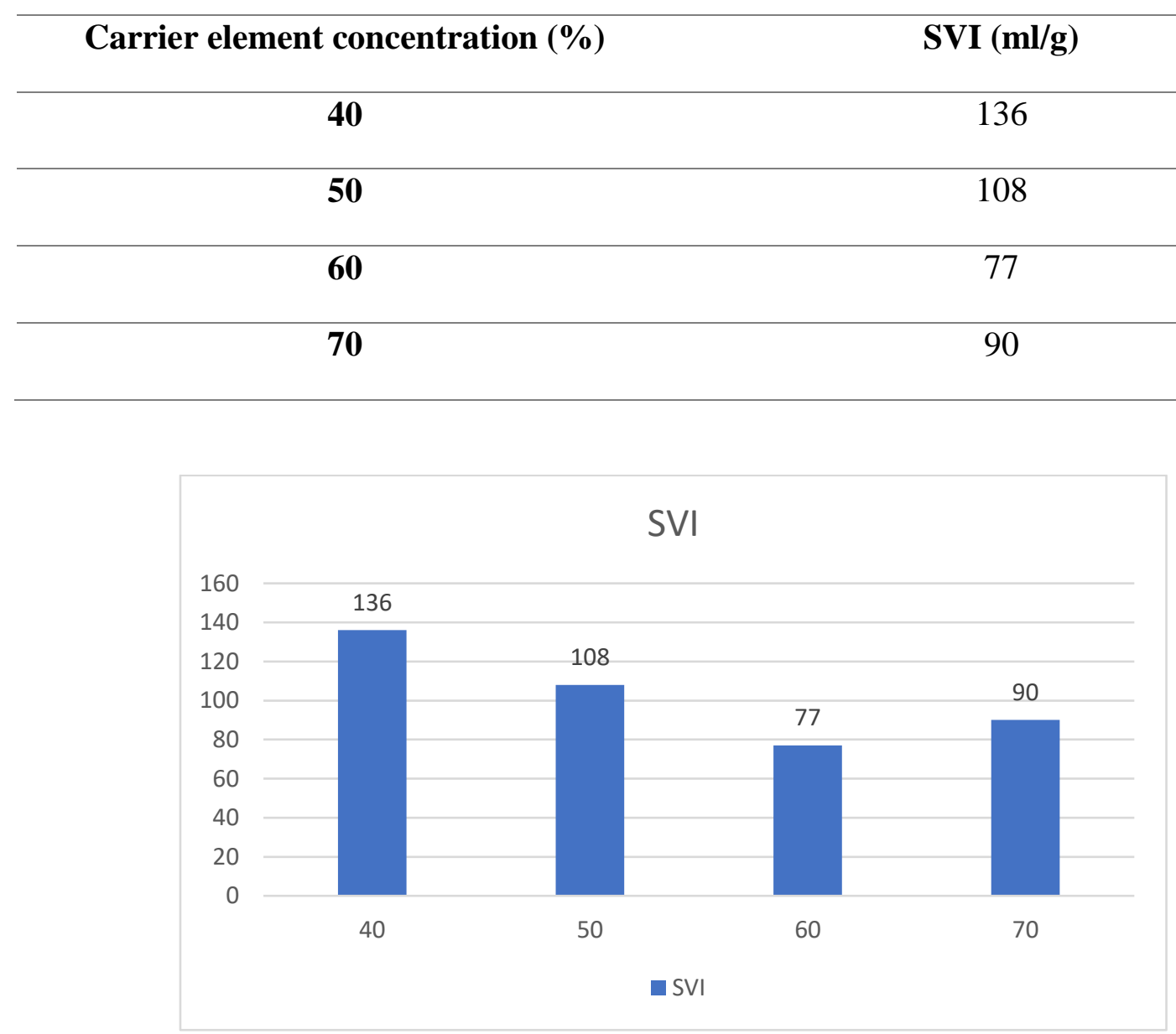

Fig 6: Graph of SVI for varying carrier element concentrations 


\subsection{COD removal:}

The effluent COD of the plant varied approximately from $200 \mathrm{mg} / \mathrm{l}$ to $850 \mathrm{mg} / \mathrm{l}$ with and average value of $500 \mathrm{Mg} / \mathrm{l}$. It was seen that with increase in carrier element fraction, COD concentration decreased. The highest COD reduction was observed at $60 \%$ carrier element ratio and the lowest at $40 \%$ carrier element ratio.

At $60 \%$ carrier element ratio, $85 \%$ COD reduction was observed.

Table 4: Average COD reduction in \% for varying carrier element concentrations

\section{Carrier element concentration (\%) Average COD removal (\%)}

$40 \quad 55$

$\mathbf{5 0} 78$

60

$70 \quad 68$

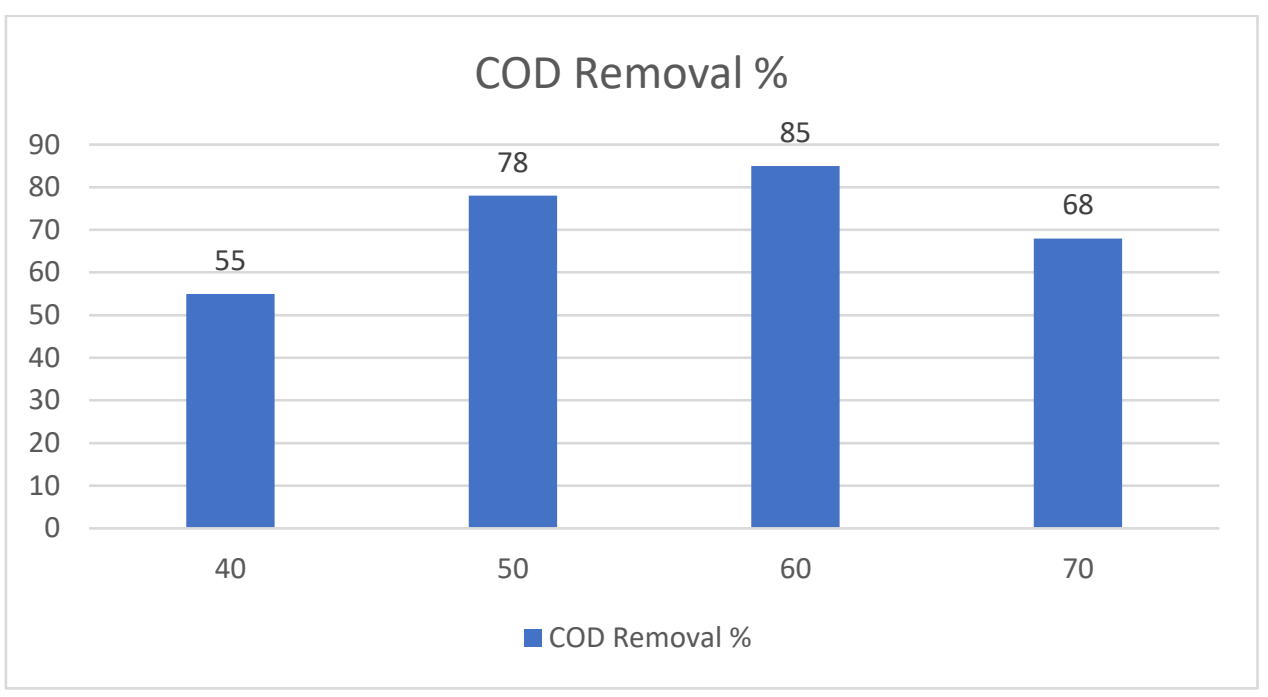

Fig 7: Graph of average COD reduction in \% for varying carrier element concentrations

Table 5: Analysis results for COD removal at varying carrier element concentration

\begin{tabular}{cccccc}
\hline $\begin{array}{c}\text { Carrier } \\
\text { element } \\
\text { fraction }\end{array}$ & $\begin{array}{c}\text { Cycle } \\
\text { number }\end{array}$ & Initial COD & Final COD & $\begin{array}{c}\text { COD } \\
\text { reduction (\%) }\end{array}$ & $\begin{array}{c}\text { Average COD } \\
\text { reduction (\%) }\end{array}$ \\
\hline $\mathbf{4 0}$ & 1 & 603 & 278 & 54 & 53 \\
& 2 & 402 & 202 & 50 & \\
\cline { 2 - 5 } & 3 & 256 & 115 & 55 & \\
\hline
\end{tabular}




\begin{tabular}{|c|c|c|c|c|c|}
\hline & 4 & 221 & 95 & 57 & \\
\hline & 5 & 239 & 106 & 56 & \\
\hline & 6 & 329 & 160 & 51 & \\
\hline \multirow[t]{6}{*}{50} & 1 & 385 & 95 & 75 & 78 \\
\hline & 2 & 402 & 83 & 79 & \\
\hline & 3 & 672 & 109 & 83 & \\
\hline & 4 & 867 & 152 & 82 & \\
\hline & 5 & 486 & 114 & 76 & \\
\hline & 6 & 675 & 192 & 71 & \\
\hline \multirow[t]{6}{*}{60} & 1 & 327 & 54 & 83 & 85 \\
\hline & 2 & 356 & 33 & 90 & \\
\hline & 3 & 438 & 79 & 82 & \\
\hline & 4 & 552 & 100 & 82 & \\
\hline & 5 & 397 & 56 & 86 & \\
\hline & 6 & 462 & 78 & 83 & \\
\hline \multirow[t]{6}{*}{70} & 1 & 580 & 286 & 50 & 68 \\
\hline & 2 & 640 & 207 & 68 & \\
\hline & 3 & 341 & 80 & 76 & \\
\hline & 4 & 211 & 50 & 76 & \\
\hline & 5 & 487 & 157 & 67 & \\
\hline & 6 & 346 & 65 & 81 & \\
\hline
\end{tabular}

2.4 P removal:

MBBR acts as a biological phosphorus removal process utilizing bacterial capabilities to take up phosphorus as the bacteria grow in the system. The bacteria responsible for $\mathrm{P}$ removal are phosphorus accumulating organisms (PAOs) which play a significant role in phosphorus removal. The influent concentrations of Phosphate varied from 18 to $24 \mathrm{mg} / \mathrm{L}$. The average value of Phosphate of effluent was around $22 \mathrm{mg} / \mathrm{L}$. Lowest phosphate removal was observed at $40 \%$ and the highest phosphate removal was observed at $60 \%$ 
Table 6: Average phosphate reduction in \% for varying carrier element concentrations

\begin{tabular}{cc}
\hline Carrier element concentration (\%) & Average phosphate removal \% \\
\hline $\mathbf{4 0}$ & 33 \\
\hline $\mathbf{5 0}$ & 41 \\
\hline $\mathbf{6 0}$ & 65 \\
\hline $\mathbf{7 0}$ & 44 \\
\hline
\end{tabular}

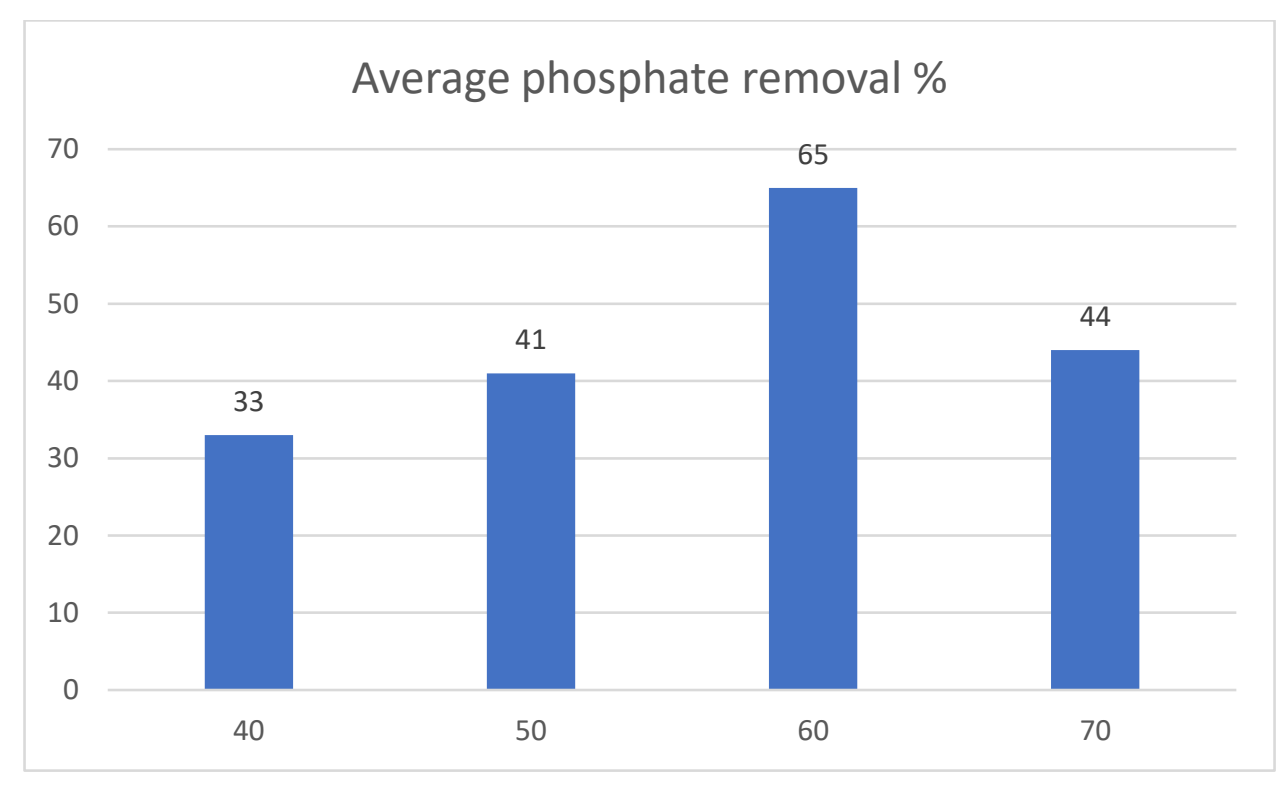

Fig 8: Graph of phosphorus removal at varying carrier element concentrations

3. Conclusion:

The influence of carrier element fraction in MBBR on biological treatment is evident.

- When the carrier element fraction was varied between $40 \%$ to $70 \%$ the average COD removal rate was increased from $53 \%$ to $85 \%$ and then dropped to $68 \%$, the optimum carrier element fraction for removal of COD from the effluent used for study was about $60 \%$. The average phosphate removal was elevated from $33 \%$ to $65 \%$ at $60 \%$ carrier element fraction.

- As the carrier element fraction increased, the average biomass concentration of the suspended sludge had a decreasing trend. The MLSS was considerably reduced at $60 \%$ carrier element fraction and was found to be around $2500-3000 \mathrm{mg} / \mathrm{l}$ which meets the design criteria. As a result, the sludge production was reduced too.

In conclusion, it can be said that the optimum carrier element fraction for the effluent under study was found to be $60 \%$ 
The results of the pilot study were presented to the top management of the industry \& they have agreed to procure MBBR media in 2020 to ensure $60 \%$ carrier element fraction at the effluent plant's MBBR.

4. References

i. Rong Chang Wang et.al, State key laboratory of Pollution Control and Resource Reuse, School of Environmental Science, "Influence of carrier concentration on the performance and microbial characteristics of a suspended carrier biofilm reactor", Process Biochemistry 40(2005)2992-3001

ii. Metcalf and Eddy, 'Waste Water Engineering Treatment and Reuse', 4th edition, Tata McGraw Hill Publishers, 2003

iii. Shuai Yang et.al, Key laboratory of Industrial Ecology and Environmental Engineering, MOE, School of Environmental and Biological Science and Technology, "Simultaneous nitrogen and phosphorus removal by a novel sequencing batch moving bed membrane bioreactor for wastewater treatment", Journal of Hazardous Materials 175 (2010) 551-557

iv. Qiyuan Gu et.al, School of civil and environmental engineering, University of science and technology Beijing, "Influence of carrier filling ratio on the performance of moving bed biofilm reactor in treating coking wastewater", Bioresource Technology 166 (2014) 71- 8

v. Dr. Mudhaffar S. Al-Zuhairy et.al, Southern Technical University/Baghdad, "Biological Phosphorus and Nitrogen Removal from Wastewater Using Moving Bed Biofilm Reactor (MBBR)”, Eng. \&Tech.Journal, Vol.33,Part (A), No.7, 2015

vi. Hallvard Odegaard, Faculty of civil and environmental engineering, Norwegian University of Science and Technology (NTNU), N-7491, Trondheim, Norway, "Advanced compact wastewater treatment based on coagulation and moving bed biofilm processes" 